\title{
Shock safety modelling of indirect contact with low-voltage electric devices
}

\author{
WLODZIMIERZ KORNILUK, DARIUSZ SAJEWICZ \\ Bialystok University of Technology \\ Wiejska 45D, 15-351 Biatystok, Poland \\ e-mail:korniluk@pb.edu.pl,darsaj@op.pl
}

(Received: 22.03.2011, revised: 19.04.2011)

\begin{abstract}
The article presents a shock safety model of an indirect contact with a lowvoltage electric device. This model was used for computations and analyses concerning the following: the probabilities of appearance of the particular shock protection unreliability states, electric shock states (ventricular fibrillation), contributions of the unreliability of different shock protection elements to the probability of occurrence of these states, as well as the risk of electric shock (and the shock safety), and contributions of the intensity of occurrence of damages to different shock protection elements to this risk. An example of a possibility to reduce the risk of an electric shock through changing the intensity of occurrence of damages to the selected protection elements was provided.

Key words: safety management process, expert system, Bayesian network, total probability, protection reliability states, appearance of touch and electric shock states, risk analysis and assessment
\end{abstract}

\section{Introduction}

In the process of shock safety management, the following tasks are performed, among others [1-3]: investigating electric shock incidents, analysing and assessing shock risks, as well as determining criteria of dimensioning shock protection means. The created expert system, supporting performance of these tasks [4], should have a knowledge base equipped with an appropriate shock safety model. Considering the characteristics of these tasks, a method of modelling the shock protection reliability and shock safety of low-voltage devices [5] was developed.

The suggested shock safety modelling method [5] consists in mapping - with the use of a Bayesian network - the total probability of appearance of different combinations of the considered damages and a lack of damages of the particular elements of shock protection means. The next stage comprises a computer identification of various touch scenarios (touch voltage appearing in the considered areas of contacting parts of electric devices). The probabilities of 
appearance of touch effects on the basis of the touch voltage values and its duration as well as other pre-set circumstances and factors affecting the shock occurrence for the identified touch scenarios are subsequently determined. Such a method of modelling shock safety makes it possible to determine the probabilities and intensity of appearance of unreliability and shock states.

The article describes an example of applying the developed method to modelling shock safety in the case of an indirect contact with low-voltage electric devices.

The article includes the results of computations and analyses concerning:

- the probabilities of occurrence of different states of protection unreliability and of electric shock (ventricular fibrillation) as well as the contributions of the unreliability of different shock protection elements to the probability of occurrence of these states;

- the risk of an electric shock (and shock safety) as well as the contributions of the intensity of damages to the particular protection elements to this risk;

- the possibilities of reducing the risk of an electric shock.

\section{Example of safety model}

The developed shock safety model concerns shock protection against an indirect contact $[6,7]$ (auto power-off) for one of the devices installed in the wiring system of a single-family house connected to a single-phase TN-C-S system (Fig. 1).

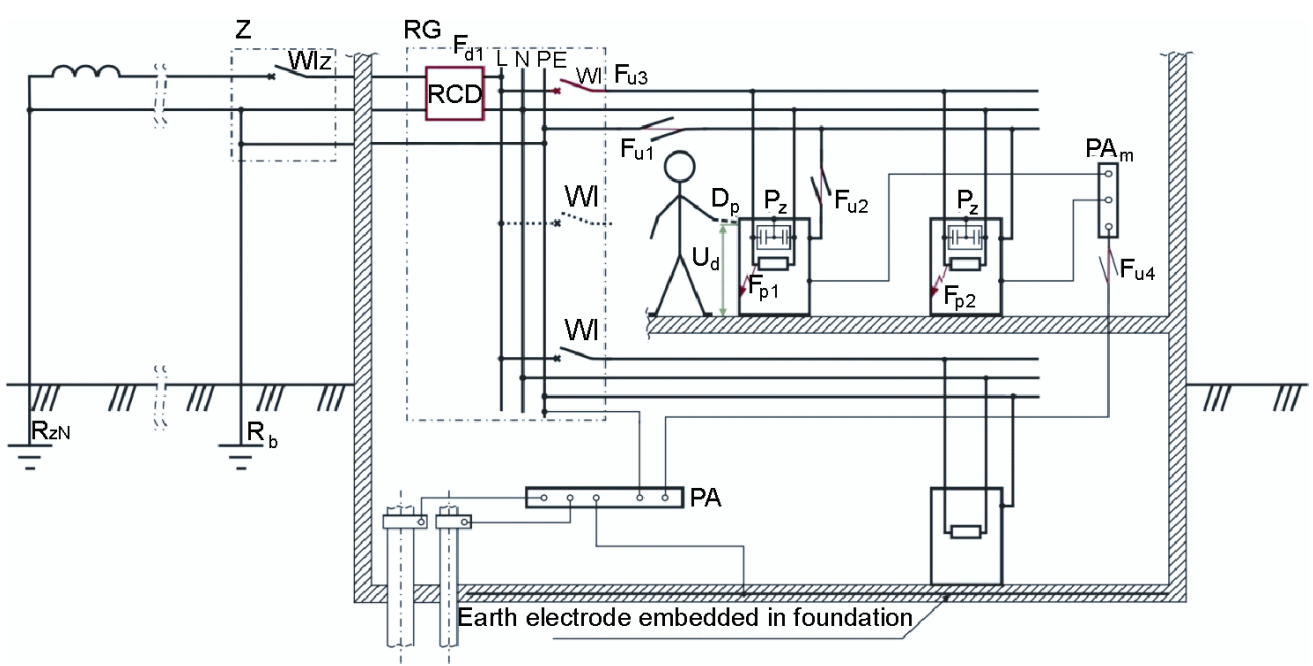

Fig. 1. Diagram of wiring system of single-family house connected to TN-C-S system. Symbols: $Z-$ outdoor connector, $P A$ - Main Equipotential Bonding, $P A_{m}$ - Local Equipotential Bonding, $R G$ - main switchgear, $R_{z N}$ - earthing of system neutral point, $R_{b}$ - earthing of PEN wire, Wiz, WI - circuit breakers, $R C D$ - high-sensitivity residual-current device, $P_{z}$ - interference eliminator, $F_{p i}, F_{u i}$ and $F_{d l}$ - faults accounted for in reliability model of shock protection against indirect contact with one of devices 
The occurrence of the following types of protection was included in the model:

- basic protection: damage (a short circuit) to the basic insulation of the $F_{p 1}$ and $F_{p 2}$ devices;

- fault protection: an $\left(F_{u 1}\right)$ discontinuity of a PE protective conductor, an $\left(F_{u 2}\right)$ discontinuity of a PE protective conductor, a state of $\left(F_{u 3}\right)$ fault condition of a protective device, and an $\left(F_{u 4}\right)$ discontinuity of the $P w$ protective bonding;

- additional protection: a state of $\left(F_{d 1}\right)$ fault condition of the high-sensitivity residual-current device.

The limited number of damages to shock protection elements, analysed in the developed shock safety model, results from the necessity to simplify the model in order to illustrate the idea of the developed method well and to ensure clear demonstration of the obtained computation results.

Figure 2 shows a Bayesian network illustrating a shock safety model for an electric device in the case of a $D_{p}$ indirect contact.

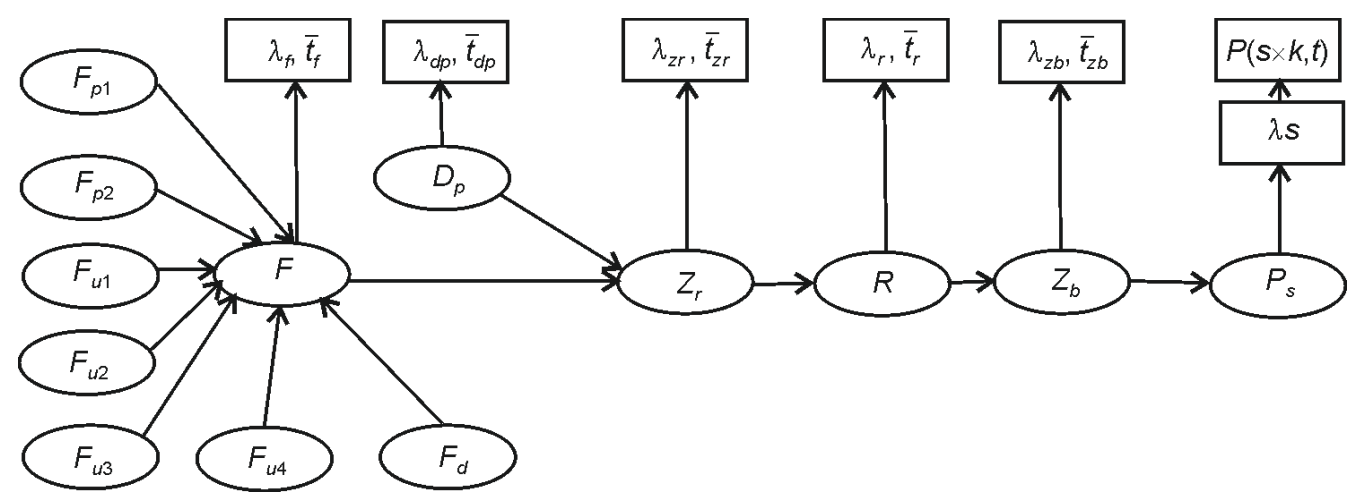

Fig. 2. Structure of Bayesian network illustrating shock safety model for indirect contact with one of devices installed in wiring system of single-family house (Fig.1). Symbols are explained in the text

The CPT of the $F$ conditional node (Fig. 1) includes the values of probabilities representing 128 combinations of unreliability states for shock protection elements in an indirect contact.

The following reliability states were identified in the developed shock safety model: 128 states of a lack of touch danger (a lack of damage or contact), 127 states of touch danger (a damage and contact occurred), 104 states (scenarios) of touch (8 states as a result of fault protection damage and 96 states resulting from basic protection damage), out of which 11 appeared in states of a lack of safety (protection) unreliability, and 93 in states of safety (protection) unreliability.

Eight scenarios of touch, which occur in the case of damage to fault protection elements (PE protective conductor and $P w$ protective bonding breaks) were considered; $f_{u 1}$ and $f_{u 4}$ occur as a result of using $P_{z}$ interference eliminators in devices (Fig. 3). Electric network precipitators in electric devices are required in order to conform to the requirements of electromagnetic compatibility standards [8] concerning susceptibility and interference emissions. The structure of an asymmetric interference filter is shown in Figure 3a: condensers of the same 
capacity, connected to the device cover, cause a small leakage in the PE protective conductor, whereas in the case when this terminal is broken (forming a reactance divider), they make the device cover potential raise to a dangerous level. A diagram of a touch circuit resulting from breaking PE protective conductors is presented in Figure $3 \mathrm{~b}$.

a)

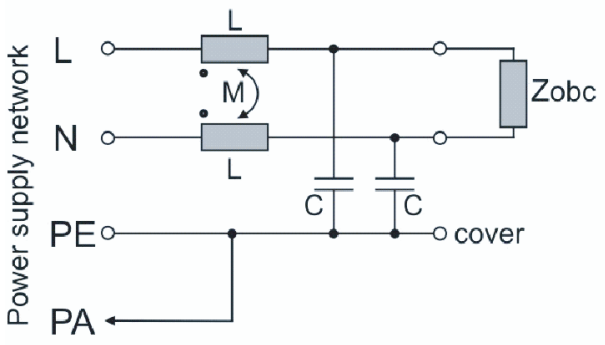

b)

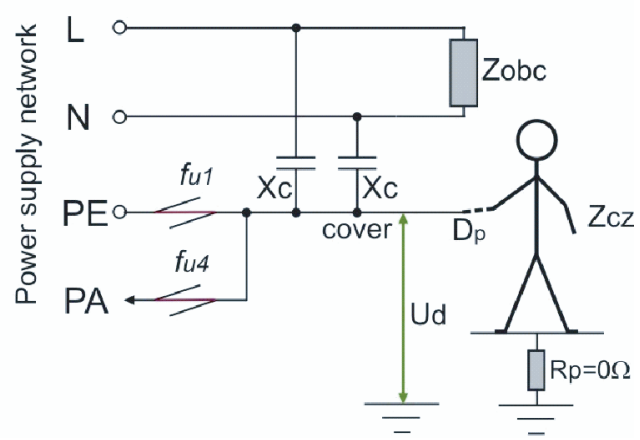

Fig. 3. Touch situations in the case of damage to fault protection elements $\left(f_{u 1}\right.$ PE protective conductor and $f_{u 4} \mathrm{Pw}$ protective bonding breaks) a) structure of electric network precipitator at no damage, b) touch circuit resulting form breaking $\mathrm{PE}$ and $P w$ wires

Identification of touch states, i.e. verifying whether touch voltage occurred for the particular combinations of unreliability states of shock protection elements and contacts, was performed on the basis of analysing the wiring system diagram (Fig. 1).

The performed computations and analyses concerned:

- the probabilities of occurrence of the particular states of protection unreliability and states of electric shock (ventricular fibrillation) as well as their selected rankings;

- the relative contributions of unreliability of the particular protection elements to the protection system unreliability and probability of occurrence of the state of an electric shock;

- the risk of an electric shock (and the shock safety);

- the relative contributions of the intensity of damage to the particular protection elements to the risk of an electric shock;

- possibilities of reducing the risk of an electric shock.

The computations and their analysis were carried out using a spreadsheet developed in the OFFICE EXCEL computer application. The adopted reliability parameter values for shock protection elements before an indirect contact on the basis of $[9,10]$ are listed in Table 1 . The computations were performed for the $P\left(d_{p}\right)=0.9$ probability of contacting a device.

The $P\left(s / \bar{z}_{b_{u}}\right)$ and $P\left(s / z_{b_{v}}\right)$ probabilities of occurrence of ventricular fibrillation were determined separately for each shock scenario, applying the method presented in the [11] paper. The computations were carried out for the following touch conditions: the wet epidermis state, the left hand-feet (lh-ff) touch path, the temperature of the surroundings $T=20^{\circ} \mathrm{C}$, $S_{1}=82 \mathrm{~cm}^{2}, S_{2}=164 \mathrm{~cm}^{2}$ electrode contact areas, $m=12 \mathrm{~kg}$ the body weight of a human (a child). 
Table 1. List of values of reliability parameters of shock protection elements, adopted for computations before indirect contact with electric device (Fig. 1)

\begin{tabular}{|c|c|c|}
\hline Type of damage to shock protection element & Parameter & Parameter values \\
\hline \multirow{2}{*}{$\begin{array}{l}\left(f_{u 1}\right) \text { discontinuity of } P E \text { protective } \\
\text { conductor }\end{array}$} & $\lambda_{f_{u 1}}[1 / a]$ & $10^{-1}, 10^{-2}$, or $5 \cdot 10^{-2}$ \\
\hline & $T_{k u 1}[\mathrm{a}]$ & 1,2, or 5 \\
\hline \multirow{3}{*}{$\begin{array}{l}\left(f_{p 1}\right) \text { damage (short circuit) to basic } \\
\text { protection in device }\end{array}$} & $\lambda_{f_{p 1}}[1 / a]$ & $10^{-1}, 10^{-2}$, or $5 \cdot 10^{-2}$ \\
\hline & $t_{w y l 1}[\mathrm{a}]$ & at auto power-off $1.27 \cdot 10^{-8}$ \\
\hline & $T_{k p 1}[\mathrm{a}]$ & 1,2, or 5 \\
\hline \multirow{3}{*}{$\begin{array}{l}\left(f_{p 2}\right) \text { damage (short circuit) to basic } \\
\text { protection in device }\end{array}$} & $\lambda_{f_{p 2}}[1 / a]$ & $10^{-1}, 10^{-2}$, or $5 \cdot 10^{-2}$ \\
\hline & $t_{w y / 2}[\mathrm{a}]$ & at auto power-off $1.27 \cdot 10^{-8}$ \\
\hline & $T_{k p 2}[\mathrm{a}]$ & 1,2, or 5 \\
\hline \multirow{2}{*}{$\begin{array}{l}\left(f_{u 2}\right) \text { discontinuity of } P E \text { protective } \\
\text { conductor }\end{array}$} & $\lambda_{f_{u 2}}[1 / a]$ & $10^{-1}, 10^{-2}$, or $5 \cdot 10^{-2}$ \\
\hline & $T_{k u 2}[\mathrm{a}]$ & 1,2, or 5 \\
\hline \multirow{2}{*}{$\begin{array}{l}\left(f_{u 3}\right) \text { state of fault condition of protective } \\
\text { device }\end{array}$} & $\lambda_{f_{u 3}}[1 / a]$ & $7.95 \cdot 10^{-2}$ \\
\hline & $T_{k u 3}[\mathrm{a}]$ & 1,2, or 5 \\
\hline \multirow{2}{*}{$\begin{array}{l}\left(f_{d 1}\right) \text { state of fault condition of high- } \\
\text { sensitivity residual-current device }\end{array}$} & $\lambda_{f_{d 1}}[1 / a]$ & $7 \cdot 10^{-3}$ \\
\hline & $T_{k d 1}[\mathrm{a}]$ & $1 / 12$ \\
\hline \multirow{2}{*}{$\left(f_{u 4}\right) P w$ protective bonding discontinuity } & $\lambda_{f_{u 4}}[1 / a]$ & $10^{-1}, 10^{-2}$, or $5 \cdot 10^{-2}$ \\
\hline & $T_{k u 4}[\mathrm{a}]$ & 1,2, or 5 \\
\hline
\end{tabular}

Table 2. List of touch voltage values and touch duration times, adopted for computations, and calculated conditional probabilities of occurrence of result in the form of ventricular fibrillation

\begin{tabular}{c|c|c|c|c|c}
\hline No. & Protection damage & $U_{d}[\mathrm{~V}]$ & $t_{r}[\mathrm{~s}]$ & $P\left(s / F_{p 1}, \ldots, F_{d 1}\right)$ & $\begin{array}{c}\text { Number } \\
\text { of scenarios }\end{array}$ \\
\hline \multirow{2}{*}{1} & $f_{p 1}$ or $f_{p 2}$ basic protection & 40 & 0.4 & $1.22 \cdot 10^{-15}$ & 37 \\
\cline { 4 - 6 } 2 & 50 & 5 & $9.26 \cdot 10^{-7}$ & 8 \\
\hline \multirow{2}{*}{2} & $\begin{array}{c}f_{p 1} \text { or } f_{p 2} \text { basic protection } \\
f_{u 4} \text { fault protection }\end{array}$ & 80 & 0.4 & $3.24 \cdot 10^{-10}$ & 14 \\
\cline { 4 - 6 } 3 & $f_{u 1}$ and $f_{u 4}$ fault protection & 16 & 10 & $2.48 \cdot 10^{-14}$ & 8 \\
\hline \multirow{2}{*}{4} & $\begin{array}{c}f_{p 1} \text { or } f_{p 2} \text { basic protection } \\
f_{u 1} \vee f_{u 2} \text { and } f_{u 4} \text { fault protection } \\
f_{d 1} \text { additional protection }\end{array}$ & 230 & 10 & 0.59 & 28 \\
\hline
\end{tabular}

The adopted touch voltage values ranged from several volts (when only the basic protection was damaged) to $230 \mathrm{~V}$ (damaged basic protection, and broken $P E$ and $P w$ ). The adopted 
touch duration times resulted from the allowed operating times for particular protection means [12] or, in the cases when the power is not switched off quickly, the time of $10 \mathrm{~s}$ was adopted. The results of calculating $P\left(s / F_{p 1}, \ldots, F_{d 1}\right)$ conditional probabilities of occurrence of a result in the form of ventricular fibrillation in the particular shock scenarios for the adopted $U_{d}$ touch voltage values and the $t_{r}$ touch duration times are listed in Table 2 .

The selected results pertaining to the probabilities and intensity of occurrence of unreliability states of protection elements at an indirect contact as well as the reliability states of shock protection at indirect contacts with electric devices (Fig. 1) are listed in Tables 3 and 4. The results indicate that the probability of occurrence of the touch state decreases with the increase of the ensured reliability of protection elements (through reducing $\lambda_{f}$ and/or $T_{k}$ ).

Table 3. Probability of occurrence of shock protection unreliability states at indirect contact with electric devices (Fig. 1)

\begin{tabular}{|c|c|c|c|c|c|c|}
\hline$\lambda_{f x}[1 / \mathrm{a}]$ & $T_{k}[a]$ & $P(f)$ & $P\left(z_{r}\right)$ & $P(r)$ & $P\left(\bar{z}_{b}\right)$ & $P\left(z_{b}\right)$ \\
\hline \multirow{3}{*}{0.1} & 5 & 0.606 & \begin{tabular}{|l|}
0.545 \\
\end{tabular} & $6 * 10^{-2}$ & $3.8 * 10^{-2}$ & $2.2 * 10^{-2}$ \\
\hline & 2 & 0.312 & 0.281 & $9.8 * 10^{-3}$ & $7.8^{*} 10^{-3}$ & $2 * 10^{-3}$ \\
\hline & 1 & 0.172 & 0.154 & $2.4 * 10^{-3}$ & $2.1 * 10^{-3}$ & $3 * 10^{-4}$ \\
\hline \multirow{3}{*}{0.05} & 5 & 0.430 & 0.387 & $1.5 * 10^{-2}$ & $1.1 * 10^{-2}$ & $4 * 10^{-3}$ \\
\hline & 2 & 0.203 & 0.183 & $2.4 * 10^{-3}$ & $2.1 * 10^{-3}$ & $3 * 10^{-4}$ \\
\hline & 1 & 0.108 & 0.097 & $5.8 * 10^{-4}$ & $5.4 * 10^{-4}$ & $4 * 10^{-5}$ \\
\hline \multirow{3}{*}{0.01} & 5 & 0.234 & 0.211 & $5.8 * 10^{-4}$ & $5.4 * 10^{-4}$ & $4 * 10^{-5}$ \\
\hline & 2 & 0.103 & 0.092 & $9.18 * 10^{-5}$ & $8.88 * 10^{-5}$ & $3 * 10^{-6}$ \\
\hline & 1 & 0.053 & 0.048 & $2.27 * 10^{-5}$ & $2.235 * 10^{-5}$ & $3.5^{*} 10^{-7}$ \\
\hline \multicolumn{7}{|c|}{$\begin{array}{c}\text { Determined for: } \lambda_{f x}=\lambda_{f p 1}=\lambda_{f p 2}=\lambda_{f u 1}=\lambda_{f u 2}=\lambda_{f u 4}, \\
\lambda_{f u 3}=0.07951 / \mathrm{a} \text { and } \lambda_{f d 1}=0.0071 / \mathrm{a}\end{array}$} \\
\hline
\end{tabular}

Table 4. Results of calculating intensity of occurrence of protection elements unreliability states at indirect contact with electric devices and shock protection reliability states (Fig. 1)

\begin{tabular}{|c|c|c|c|c|c|c|}
\hline$\lambda_{f x}[1 / \mathrm{a}]$ & $T_{k}[a]$ & $\lambda_{x}[1 / \mathrm{a}]$ & $\lambda_{z_{r}}[1 / a]$ & $\lambda_{r}[1 / \mathrm{a}]$ & $\lambda_{z_{b}}[1 / a]$ & $\lambda_{z_{b}}[1 / a]$ \\
\hline \multirow{3}{*}{0.1} & 5 & \multirow{3}{*}{0.587} & \multirow{3}{*}{0.528} & 0.245 & 0.128 & 0.117 \\
\hline & 2 & & & 0.206 & 0.167 & 0.039 \\
\hline & 1 & & & 0.190 & 0.164 & 0.026 \\
\hline \multirow{3}{*}{0.05} & 5 & \multirow{3}{*}{0.337} & \multirow{3}{*}{0.304} & 0.105 & 0.074 & 0.031 \\
\hline & 2 & & & 0.095 & 0.082 & 0.013 \\
\hline & 1 & & & 0.092 & 0.085 & 0.007 \\
\hline \multirow{3}{*}{0.01} & 5 & \multirow{3}{*}{0.136} & \multirow{3}{*}{0.123} & 0.018 & 0.0171 & $9 * 10^{-4}$ \\
\hline & 2 & & & 0.018 & 0.0176 & $4 * 10^{-4}$ \\
\hline & 1 & & & 0.018 & 0.0178 & $2 * 10^{-4}$ \\
\hline
\end{tabular}

Determined for: $\lambda_{f x}=\lambda_{f p 1}=\lambda_{f p 2}=\lambda_{f u 1}=\lambda_{f u 2}=\lambda_{f u 4}$, $\lambda_{f u 3}=0.07951 / \mathrm{a}$ and $\lambda_{f d 1}=0.0071 / \mathrm{a}$ 
The total probability of 104 touch scenarios amounts to $P(r)=5.8 \cdot 10^{-4}$ (calculated for the case where $\lambda_{f x}=0.011 / a, \lambda_{f i 3}=0.07951 / a, \lambda_{f d 1}=0.0071 / a$, and $T_{k}=5 \mathrm{a}$ ). Out of these touch scenarios, the following have the highest probability of occurrence:

- the first scenario

$$
\begin{gathered}
P\left(r_{1}\right)=P\left(\bar{f}_{p 1 w y l}\right) \cdot P\left(\bar{f}_{p 2 w y l}\right) \cdot P\left(f_{u 1}\right) \cdot P\left(\bar{f}_{u 2}\right) \cdot P\left(\bar{f}_{u 3}\right) \cdot P\left(f_{u 4}\right) \cdot P\left(\bar{f}_{d 1}\right)=4.35 \cdot 10^{-4}, \\
P\left(r_{1}\right) / P(r) \cdot 100 \%=75 \%,
\end{gathered}
$$

- the second scenario

$$
\begin{gathered}
P\left(r_{2}\right)=P\left(f_{p 1}\right) \cdot P\left(\bar{f}_{p 2 w y t}\right) \cdot P\left(\bar{f}_{u 1}\right) \cdot P\left(\bar{f}_{u 2}\right) \cdot P\left(\bar{f}_{u 3}\right) \cdot P\left(f_{u 4}\right) \cdot P\left(\bar{f}_{d 1}\right)=1.07 \cdot 10^{-5}, \\
P\left(r_{2}\right) / P(r) \cdot 100 \%=1.86 \%
\end{gathered}
$$

- the third scenario

$$
\begin{gathered}
P\left(r_{3}\right)=P\left(\bar{f}_{p 1 w y t}\right) \cdot P\left(f_{p 2}\right) \cdot P\left(\bar{f}_{u 1}\right) \cdot P\left(f_{u 2}\right) \cdot P\left(\bar{f}_{u 3}\right) \cdot P\left(f_{u 4}\right) \cdot P\left(\bar{f}_{d 1}\right)=1.07 \cdot 10^{-5}, \\
P\left(r_{3}\right) / P(r) \cdot 100 \%=1.86 \% .
\end{gathered}
$$

The total intensity of the 104 touch scenarios equals $\lambda_{r}=1.86 \quad 10^{-2} 1 / a$ (calculated for the case where $\lambda_{f x}=0.011 / a, \lambda_{f u 3}=0.07951 / a, \lambda_{f d 1}=0.0071 / a$, and $\left.T_{k}=5 a\right)$. Out of these touch scenarios, the following are characterised by the greatest intensity of occurrence:

- the first scenario

$$
\begin{gathered}
\lambda_{n_{1}}=P\left(f_{p 1 w y t}\right) \cdot P\left(\bar{f}_{p 2 w y t}\right) \cdot P\left(\bar{f}_{u 1}\right) \cdot P\left(\bar{f}_{u 2}\right) \cdot P\left(\bar{f}_{u 3 w y t}\right) \cdot P\left(\bar{f}_{u 4}\right) \cdot P\left(\bar{f}_{d 1}\right)=8.35 \cdot 10^{-3} 1 / a, \\
\lambda_{n_{1}} / \lambda_{r} \cdot 100 \%=44.9 \%,
\end{gathered}
$$

- the second scenario

$$
\begin{gathered}
\lambda_{r_{2}}=P\left(\bar{f}_{p 1 w y t}\right) \cdot P\left(\bar{f}_{p 2 w y t}\right) \cdot P\left(\bar{f}_{u 1}\right) \cdot P\left(f_{u 2}\right) \cdot P\left(\bar{f}_{u 3}\right) \cdot P\left(f_{u 4}\right) \cdot P\left(f_{d 1}\right)=3.56 \cdot 10^{-4} 1 / a, \\
\lambda_{r_{2}} / \lambda_{r} \cdot 100 \%=1.91 \%,
\end{gathered}
$$

- the third scenario

$$
\begin{gathered}
\lambda_{r_{3}}=P\left(f_{p 1 w y t}\right) \cdot P\left(\bar{f}_{p 2 w y t}\right) \cdot P\left(\bar{f}_{u 1}\right) \cdot P\left(\bar{f}_{u 2}\right) \cdot P\left(\bar{f}_{u 3 w y t}\right) \cdot P\left(f_{u 4}\right) \cdot P\left(\bar{f}_{d 1}\right)=2.10 \cdot 10^{-4} 1 / a, \\
\lambda_{r_{3}} / \lambda_{r} \cdot 100 \%=1.13 \% .
\end{gathered}
$$

The relative contributions of $\left(f_{p 1}, f_{p 2}\right)$ unreliability of the particular basic, $\left(f_{u 1}, f_{u 2}, f_{u 3}, f_{u 4}\right)$ fault, and $\left(f_{d 1}\right)$ additional protection elements to the $P(r)$ probability as well as the relative contributions of the damage intensity of these elements to the $\lambda_{r}$ intensity of touch states at an indirect contact with electric devices (Fig. 1) are shown in Figure 4.

Relative contributions of unreliability of the particular basic, fault, and additional protection elements to the $P(r)$ probability of occurrence of touch can be successfully applied to determine the most probable touch scenario occurring in the event of an electrical accident. 
a)

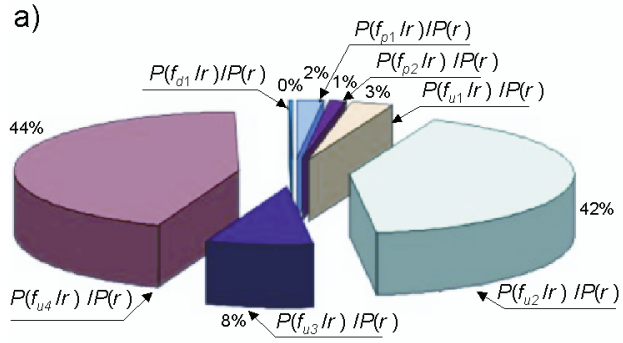

b)

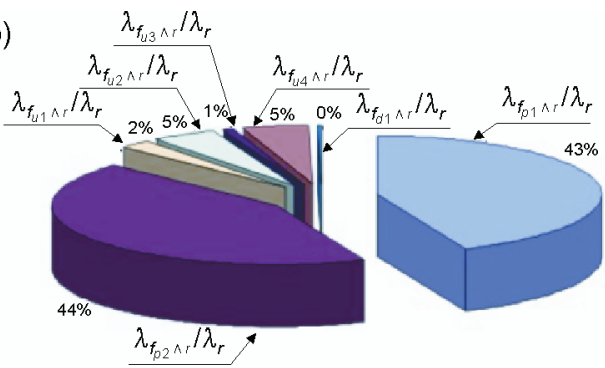

Fig. 4. Relative contributions of (a) unreliability of particular elements of basic $\left(f_{p 1}, f_{p 2}\right)$, fault $\left(f_{u 1}, f_{u 2}, f_{u 3}\right.$, $\left.f_{u 4}\right)$ and additional $\left(f_{d l}\right)$ protection to $P(r)$ probability of occurrence of touch states and (b) intensity of damage to protection elements to $\lambda_{r}$ intensity of occurrence of touch states at indirect contacts with electric devices. Calculations were performed for $\lambda_{f x}=0.011 / a, \lambda_{f u 3}=0.07951 / a, \lambda_{f d 1}=0.0071 / a$, intensities and $T_{k}=5 a$ inspection time. Symbols for damages and states of fault condition as in Figure 1

The relative distribution of contributions of unreliability of the particular protection elements to the probability of occurrence of touch (Fig. 4a) during an indirect contact with a device indicates that in $89 \%$ of touch scenarios, fault condition of the fault protection elements $\left(f_{u 1} \vee f_{u 2} \vee f_{u 4}\right)$ takes place. On the other hand, the relative distribution of contributions of the intensity of damages to the protection to the intensity of touch states occurrence (Fig. 4b) indicates that $87 \%$ of touch incidents are caused by the state of fault condition of the basic protection $\left(f_{u 1} \vee f_{u 2}\right)$.

The selected results concerning the probabilities of occurrence of an electric shock with a result in the form of ventricular fibrillation with a reliable $P\left(s \wedge \bar{z}_{b}\right)$ and unreliable protection $P\left(s \wedge z_{b}\right)$ as well as the total $P(s)$ at indirect contacts with electric devices (Fig. 1) are given in Table 5 .

Table 5. Probability of occurrence of electric shock with a result in the form of ventricular fibrillation with reliable $P\left(s \wedge \bar{z}_{b}\right)$ and unreliable protection $P\left(s \wedge z_{b}\right)$ as well as the total $P(s)$ at indirect contacts with electric devices (Fig. 1)

\begin{tabular}{c|c|c|c|c}
\hline$\lambda_{f x}[1 / a]$ & $T_{k}[a]$ & $P\left(s \wedge \bar{z}_{b}\right)$ & $P\left(s \wedge z_{b}\right)$ & $P(s)$ \\
\hline \multirow{3}{*}{0.1} & 5 & $9.34 * 10^{-16}$ & $1.33 * 10^{-2}$ & $1.33^{*} 10^{-2}$ \\
\cline { 2 - 5 } & 2 & $1.93 * 10^{-16}$ & $1.23 * 10^{-3}$ & $1.23 * 10^{-3}$ \\
\cline { 2 - 5 } & 1 & $5.21 * 10^{-17}$ & $1.75^{*} 10^{-4}$ & $1.75 * 10^{-4}$ \\
\hline \multirow{3}{*}{0.05} & 5 & $2.89 * 10^{-16}$ & $2.26 * 10^{-3}$ & $2.26^{*} 10^{-3}$ \\
\cline { 2 - 5 } & 2 & $5.21 * 10^{-17}$ & $1.75 * 10^{-4}$ & $1.75 * 10^{-4}$ \\
\hline \multirow{3}{*}{0.01} & 1 & $1.35 * 10^{-17}$ & $2.34 * 10^{-5}$ & $2.34 * 10^{-5}$ \\
\cline { 2 - 5 } & 5 & $1.35 * 10^{-17}$ & $2.34 * 10^{-5}$ & $2.34 * 10^{-5}$ \\
\cline { 2 - 5 } & 2 & $2.20 * 10^{-18}$ & $1.56 * 10^{-6}$ & $1.56^{*} 10^{-6}$ \\
\hline
\end{tabular}

Determined for: $\lambda_{f x}=\lambda_{f p 1}=\lambda_{f p 2}=\lambda_{f u 1}=\lambda_{f u 2}=\lambda_{f u 4}, \lambda_{f u 3}=0.07951 / a$ and $\lambda_{f d 1}=0.0071 / a$ 
Table 6. $\lambda_{s}$ intensity of occurrence of electric shock with a result in the form of ventricular fibrillation (divided into states with a reliable $\lambda_{s \wedge \bar{z}_{b}}$ and unreliable $\lambda_{s \wedge z_{b}}$ protection) and $P(s \times k=0, t=1 a)$ probabilities of nonoccurrence of electric shock within one year at indirect contact with electric devices (Fig. 1)

\begin{tabular}{c|c|c|c|c|c}
\hline$\lambda_{f \times}[1 / a]$ & $T_{k}[a]$ & $\lambda_{s \wedge \bar{z}_{b}}$ & $\lambda_{s \wedge z_{b}}$ & $\lambda_{s}$ & $P(s \times k=0, t=1 a)$ \\
\hline 0.1 & 5 & $1.82 * 10^{-17}$ & $6.86 * 10^{-5}$ & $6.86^{*} 10^{-5}$ & 0.999931 \\
\cline { 2 - 6 } & 2 & $2.37 * 10^{-18}$ & $1.97 * 10^{-6}$ & $1.97 * 10^{-6}$ & 0.999998 \\
\cline { 2 - 6 } & 1 & $3.83 * 10^{-19}$ & $9.04 * 10^{-8}$ & $9.04 * 10^{-8}$ & $\sim 1$ \\
\hline \multirow{2}{*}{0.05} & 5 & $1.78 * 10^{-18}$ & $2.17 * 10^{-6}$ & $2.17 * 10^{-6}$ & 0.999998 \\
\cline { 2 - 6 } & 2 & $1.79 * 10^{-19}$ & $4.21 * 10^{-8}$ & $4.21 * 10^{-8}$ & $\sim 1$ \\
\cline { 2 - 6 } & 1 & $2.64 * 10^{-20}$ & $1.66 * 10^{-9}$ & $1.66^{*} 10^{-9}$ & $\sim 1$ \\
\hline \multirow{2}{*}{0.01} & 5 & $4.15 * 10^{-21}$ & $2.59 * 10^{-10}$ & $2.59 * 10^{-10}$ & $\sim 1$ \\
\cline { 2 - 6 } & 2 & $3.34 * 10^{-22}$ & $3.49 * 10^{-12}$ & $3.49 * 10^{-12}$ & $\sim 1$ \\
\cline { 2 - 6 } & 1 & $4.57 * 10^{-23}$ & $1.21 * 10^{-13}$ & $1.21 * 10^{-13}$ & $\sim 1$ \\
\hline
\end{tabular}

Determined for: $\lambda_{f x}=\lambda_{f p 1}=\lambda_{f p 2}=\lambda_{f u 1}=\lambda_{f u 2}=\lambda_{f u 4}, \lambda_{f u 3}=0.07951 / a$ and $\lambda_{f d 1}=0.0071 / a$

The selected results concerning the $\lambda_{s}$ intensity of occurrence of an electric shock with a result in the form of ventricular fibrillation (divided into states with a reliable $\lambda_{s \wedge \bar{z}_{b}}$ and unreliable $\lambda_{s \wedge z_{b}}$ protection) as well as the $P(s \times k=0, t=1 a)$ probabilities of non-occurrence of an electric shock within one year at an indirect contact with electric devices (Fig. 1) are presented in Table 6. It needs to be emphasised that $\lambda_{s \wedge z_{b}}>>\lambda_{s \wedge \bar{z}_{b}}$ in all the cases, thus the intensity of occurrence of an electric shock with a result in the form of ventricular fibrillation $\lambda_{s}$ is determined by the unreliability of the shock protection elements [5].

The relative contributions of unreliability of the particular basic $\left(f_{p 1}, f_{p 2}\right)$, fault $\left(f_{u 1}, f_{u 2}, f_{u 3}, f_{u 4}\right)$, and additional $\left(f_{d 1}\right)$ protection elements to the $P(s)$ probability as well as the relative contributions of the damage intensity of these elements to the $\lambda_{s}$ intensities of occurrence of states of an electric shock at indirect contacts with electric devices (Fig. 3) are illustrated in Figure 5.

a)

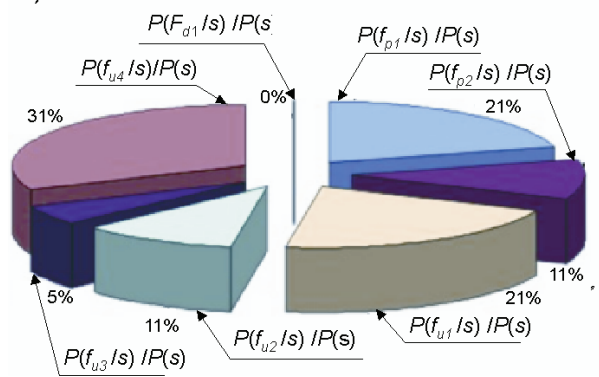

b)

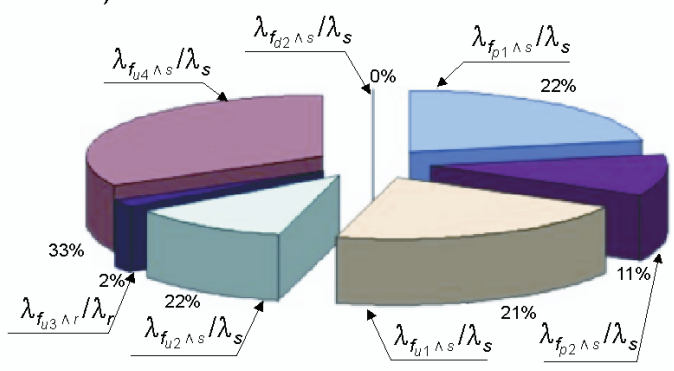

Fig. 5. Relative contributions of (a) unreliability of particular elements of basic $\left(f_{p 1}, f_{p 2}\right)$, fault $\left(f_{u 1}, f_{u 2}, f_{u 3}\right.$, $\left.f_{u 4}\right)$, and additional $\left(f_{d l}\right)$ protection to $P(s)$ probability of occurrence of a state with ventricular fibrillation and (b) intensity of damage to these elements to $\lambda_{s}$ intensity of occurrence of such states at indirect contacts with electric devices. Calculations were performed for $\lambda_{f x}=0.011 / a, \lambda_{f u 3}=0.07951 / a$, $\lambda_{f u 1}=0.0071 / a$ intensities and $T_{k}=5 a$ inspection time. Symbols for damages and states of fault condi tion as in Figure 1. 
Relative contributions of unreliability of the particular basic, fault, and additional protection elements to the $P(s)$ probability of occurrence of an electric shock (ventricular fibrillation) can be effectively used for determining the most probable shock scenario occurring during an electrical accident.

The relative distribution of contributions of unreliability of the particular protection elements of a device to the probability of occurrence of ventricular fibrillation (Fig. 5a) in the case of an indirect contact with this device indicates that in $32 \%$ of incidents of an electric shock, damage to the elements of basic protection $\left(f_{p 1} \vee f_{p 2}\right)$, and in $63 \%$ of cases damage to fault protection $\left(f_{u 1} \vee f_{u 2} \vee f_{u 4}\right)$ elements is observed, whereas the relative distribution of contributions of the intensity of damages to the protection to the intensity of an electric shock occurrence (Fig. 5b) indicates that $33 \%$ of cases of an electric shock result from $\left(f_{p 1} \vee f_{p 2}\right)$ damages to the basic protection, and $65 \%$ from $\left(f_{u 1} \vee f_{u 2} \vee f_{u 4}\right)$ fault condition of the fault protection.

The $P(s)$ probability of occurrence of the state of an electric shock with ventricular fibrillation (a), as well as (b) the $\lambda_{s}$ intensity of occurrence of such states at contacts with electric devices (Fig. 1), determined for the $\lambda_{f x}=0.011 / a, \lambda_{f u 3}=0.07951 / a, \lambda_{f u 1}=0.0071 / a$ intensities and the $T_{k}=1,2$, and $5 a$ inspection times, are listed respectively in Fig. 6 .
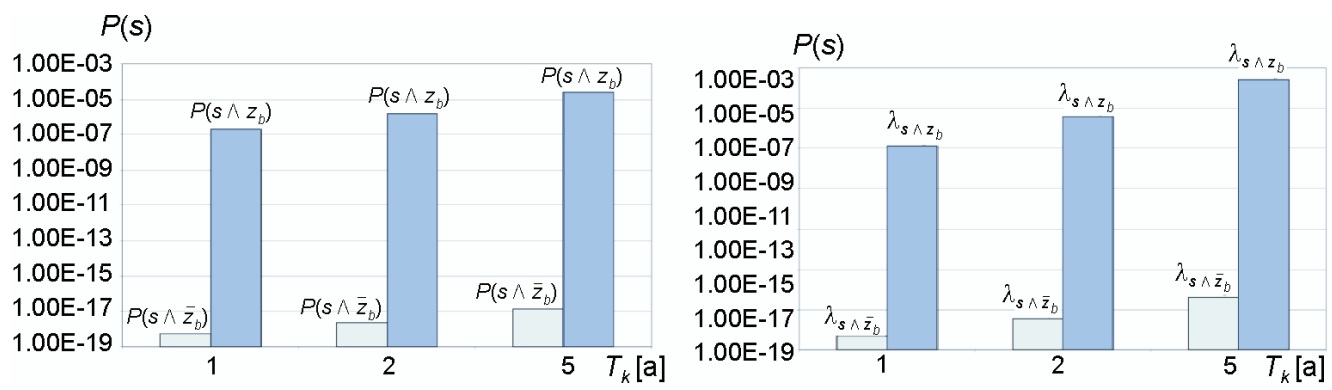

Fig. 6. $P(s)$ probability of occurrence of electric shock state with ventricular fibrillation (a) and $\lambda_{s}$ intensity of occurrence of such states (b) at contacts with electric devices for different $T_{k}$ inspection times. Calculations were carried out for $\lambda_{f x}=0.011 / a, \lambda_{f u 3}=0.07951 / a, \lambda_{f u 1}=0.0071 / a$ intensities. Symbols for damages and states of fault condition as in Figure 1

Calculations of the intensity of occurrence of an electric shock with a result in the form of ventricular fibrillation were also performed for three other variants of solving the shock protection against an indirect contact in the system under concern (Fig. 1). In the 1st variant, a high-sensitivity residual-current device and an equipotential bonding were used; in the 2nd variant there is no high-sensitivity residual-current device $\left(P\left(f_{d 1}\right)=1\right.$ and $\left.P\left(\bar{f}_{d 1}\right)=0\right)$; the 3 rd variant does not have an equipotential bonding $\left(P\left(f_{u 4}\right)=1\right.$ and $\left.P\left(\bar{f}_{u 4}\right)=1\right)$; in the 4th variant, here is no high-sensitivity residual-current device or equipotential bonding $\left(P\left(f_{d 1}\right)=1\right.$, $P\left(\bar{f}_{d 1}\right)=0$ and $\left.P\left(f_{u 4}\right)=1, P\left(\bar{f}_{u 4}\right)=1\right)$. The calculation results are presented in Table 7. 
Table 7. List of calculated intensities of occurrence of electric shock with a result in the form of ventricular fibrillation $\lambda_{s}$ (divided into states with a reliable $\lambda_{s \wedge \bar{z}_{b}}$ and unreliable $\lambda_{s \wedge z_{b}}$ protection) at indirect contact with electric devices (Fig. 1) for four variants of solving the shock protection

\begin{tabular}{|c|c|c|c|c|}
\hline $\begin{array}{c}\text { Variant of } \\
\text { protection solution }\end{array}$ & $\begin{array}{c}\text { Intensity of } \\
\text { occurrence of state }\end{array}$ & $\begin{array}{c}\text { For } \\
\lambda_{f x}=0.011 / a\end{array}$ & $\begin{array}{c}\text { For } \\
\lambda_{f x}=0.051 / a\end{array}$ & $\begin{array}{c}\text { For } \\
\lambda_{f x}=0.11 / a\end{array}$ \\
\hline \multirow{3}{*}{$\begin{array}{l}\text { 1st variant of } \\
\text { protection solution } \\
\text { with } R C D \text { and } P w\end{array}$} & $\lambda_{s}[1 / \mathrm{a}]$ shock & $2.59 \cdot 10^{-10}$ & $2.17 \cdot 10^{-6}$ & $6.86 \cdot 10^{-5}$ \\
\hline & $\begin{array}{c}\lambda_{s \wedge \bar{z}_{b}}[1 / \mathrm{a}] \text { shock with reliable } \\
\text { protection }\end{array}$ & $4.15 \cdot 10^{-21}$ & $1.18 \cdot 10^{-18}$ & $1.82 \cdot 10^{-17}$ \\
\hline & $\begin{array}{c}\lambda_{s \wedge z_{b}}[1 / \mathrm{a}] \text { shock with unreliable } \\
\text { protection }\end{array}$ & $2.59 \cdot 10^{-10}$ & $2.17 \cdot 10^{-6}$ & $6.86 \cdot 10^{-5}$ \\
\hline \multirow{3}{*}{$\begin{array}{l}2 \text { nd variant of } \\
\text { protection solution } \\
\text { with } P w \text { and } \\
\text { without } R C D\end{array}$} & $\lambda_{s}[1 / \mathrm{a}]$ shock & $2.88 \cdot 10^{-10}$ & $2.16 \cdot 10^{-6}$ & $6.84 \cdot 10^{-5}$ \\
\hline & $\begin{array}{c}\lambda_{s \wedge \bar{z}_{b}}[1 / \mathrm{a}] \text { shock with reliable } \\
\text { protection }\end{array}$ & $4.16 \cdot 10^{-21}$ & $1.77 \cdot 10^{-18}$ & $1.77 \cdot 10^{-17}$ \\
\hline & $\begin{array}{c}\lambda_{s \wedge z_{b}}[1 / \mathrm{a}] \text { shock with unreliable } \\
\text { protection }\end{array}$ & $2.88 \cdot 10^{-10}$ & $2.16 \cdot 10^{-6}$ & $6.84 \cdot 10^{-5}$ \\
\hline \multirow{3}{*}{$\begin{array}{l}\text { 3rd variant of } \\
\text { protection solution } \\
\text { protection with } \\
R C D \text { and without } \\
P w\end{array}$} & $\lambda_{s}[1 / \mathrm{a}]$ shock & $2.91 \cdot 10^{-7}$ & $1.161 \cdot 10^{-4}$ & $1.128 \cdot 10^{-3}$ \\
\hline & $\begin{array}{c}\lambda_{s \wedge \bar{z}_{b}}[1 / \mathrm{a}] \text { shock with reliable } \\
\text { protection }\end{array}$ & $3.59 \cdot 10^{-18}$ & $1.74 \cdot 10^{-18}$ & $2.49 \cdot 10^{-16}$ \\
\hline & $\begin{array}{c}\lambda_{s \wedge z_{b}}[1 / \mathrm{a}] \text { shock with unreliable } \\
\text { protection }\end{array}$ & $2.91 \cdot 10^{-7}$ & $1.161 \cdot 10^{-4}$ & $1.128 \cdot 10^{-3}$ \\
\hline \multirow{3}{*}{$\begin{array}{l}4 \text { th variant of } \\
\text { protection solution } \\
\text { protection without } \\
R C D \text { or } P w\end{array}$} & $\lambda_{s}[1 / \mathrm{a}]$ shock & $3 \cdot 10^{-7}$ & $1.165 \cdot 10^{-4}$ & $1.125 \cdot 10^{-3}$ \\
\hline & $\begin{array}{c}\lambda_{S \wedge \bar{z}_{b}}[1 / \mathrm{a}] \text { shock with reliable } \\
\text { protection }\end{array}$ & $3.62 \cdot 10^{-18}$ & $7.47 \cdot 10^{-17}$ & $2.41 \cdot 10^{-16}$ \\
\hline & $\begin{array}{c}\lambda_{s \wedge z_{b}}[1 / \mathrm{a}] \text { shock with unreliable } \\
\text { protection }\end{array}$ & $3 \cdot 10^{-7}$ & $1.165 \cdot 10^{-4}$ & $1.125 \cdot 10^{-3}$ \\
\hline \multicolumn{5}{|c|}{$\begin{array}{c}\text { Determined for: } \lambda_{f x}=0.011 / a \text { or } \lambda_{f x}=0.051 / a \text { or } \lambda_{f x}=0.11 / a, \lambda_{f u 3}=0.07951 / a, \lambda_{f d 1}=0.0071 / a \\
\text { and } T_{k}=5 a\end{array}$} \\
\hline
\end{tabular}

Shock protection is 'efficient' if the residual risk of an electric shock, represented by $\lambda_{s}$, is smaller than the tolerated $\lambda_{s} \leq \lambda_{\text {sdop }}=10^{-6} 1 / \mathrm{a}$. Such an approach is applied to criticality analysis $[13,14]$ in order to differentiate between allowed and unallowable risks. The condition of $\lambda_{s} \leq \lambda_{s d o p}=10^{-6} 1 / \mathrm{a}$ for $\lambda_{f x}=0.051 / a$ is not met by the 3 rd variant of a protection solution with an $R C D$ and without a $P w$ or the 4 th variant of a protection solution without an $R C D$ or a $P w$. The possibilities of reducing the risk of an electric shock for these variants of protection are listed in Table 8 .

Reducing the risk of an electric shock at contacts with electric devices in the considered case is possible for the $3 \mathrm{rd}$ and 4 th variants of the protection (Tab. 8) through improving the basic and fault protection reliability. 
Table 8. Possibilities of reducing risk of an electric shock for two variants of shock protection

\begin{tabular}{|c|c|c|c|c|c|}
\hline \multirow[b]{3}{*}{$\begin{array}{c}\text { Variant } \\
\text { of } \\
\text { protection } \\
\text { solution }\end{array}$} & \multirow[b]{3}{*}{$\begin{array}{c}\text { Intensity } \\
\text { of } \\
\text { occurrence } \\
\text { of state }\end{array}$} & \multicolumn{4}{|c|}{ Residual risk } \\
\hline & & & \multicolumn{3}{|c|}{ After reduction } \\
\hline & & $\begin{array}{l}\text { Without } \\
\text { reduction }\end{array}$ & $\begin{array}{c}\text { Reduction through } \\
\text { improving basic } \\
\text { protection reliability } \\
\text { from } \\
\lambda_{f p 1}=\lambda_{f p 2}=0.051 / a \\
\text { to } \lambda_{f p 1}=\lambda_{f p 2}=0.01 \quad 1 / a\end{array}$ & $\begin{array}{c}\text { Reduction through } \\
\text { improving fault } \\
\text { protection reliability } \\
\text { from } \\
\lambda_{f u 1}=\lambda_{f u 2}=0.051 / a \\
\text { to } \lambda_{f u 1}=\lambda_{f u 2}=0.011 / a\end{array}$ & $\begin{array}{c}\text { Reduction } \\
\text { through } \\
\text { improving basic } \\
\text { and fault } \\
\text { protection } \\
\text { reliability from } \\
\lambda_{f p 1}=\lambda_{f p 2}=\lambda_{f u 1} \\
\lambda_{f u 2}=0.051 / a \\
\text { to } \\
\lambda_{f p 1}=\lambda_{f p 2}==\lambda_{f u} \\
1 \lambda_{f u 2}=0.011 / a\end{array}$ \\
\hline $\begin{array}{l}\text { 3rd variant } \\
\text { of } \\
\text { protection } \\
\text { solution } \\
\text { with } R C D \\
\text { and } \\
\text { without } \\
P w\end{array}$ & $\begin{array}{c}\lambda_{s}[1 / \mathrm{a}] \\
\text { shock }\end{array}$ & $1.161 \cdot 10^{-4}$ & $5.77 \cdot 10^{-6}$ & $6.15 \cdot 10^{-6}$ & $3.05 \cdot 10^{-7}$ \\
\hline $\begin{array}{c}\text { 4th variant } \\
\text { of } \\
\text { protection } \\
\text { solution } \\
\text { without } \\
R C D \text { or } \\
P w\end{array}$ & $\begin{array}{c}\lambda_{s}[1 / \mathrm{a}] \\
\text { shock }\end{array}$ & $1.165 \cdot 10^{-4}$ & $5.82 \cdot 10^{-6}$ & $6.28 \cdot 10^{-6}$ & $3.14 \cdot 10^{-7}$ \\
\hline \multicolumn{6}{|c|}{ Determined for: $\lambda_{f x}=0.051 / a, \lambda_{f u 3}=0.07951 / a, \lambda_{f u 1}=0.0071 / a$ and $T_{k}=5 a$} \\
\hline
\end{tabular}

\section{Conclusions}

The method of modelling shock safety for low-voltage devices, based on using a Bayesian network, makes it possible to perform a comprehensive analysis and assessment of the risk of an electric shock, and also to investigate electric shock incidents and determine criteria of dimensioning shock protection means (including their reliability), which was confirmed by the calculations and analyses carried out with the use of the developed model of the protection reliability and shock safety for indirect contacts with electric devices installed in the wiring system of a single-family house.

\section{Acknowledgment}

The present work was performed within the framework of the $\mathrm{S} / \mathrm{WE} / 4 / 08$ scientific-research project 


\section{References}

[1] Korniluk W., Sobolewski R., Mathematical modelling of shock safety of electronic device - human body systems. General issues. 10th International Science and Technology Conference. Shock protection in electronic devices, pp. 75-82, Wrocław (1995).

[2] Korniluk W., Sobolewski R., Method of occupational risk assessment of electric shock associated with low-voltage equipment. Basic assumptions and algorithms. 13th International Science and Technology Conference. Electric safety. ELSAF, pp. 108-117 (2001).

[3] Korniluk W., Sobolewski R., Method of occupational risk assessment of electric shock associated with low-voltage equipment. Mathematical models of risk. 13th International Science and Technology Conference. Electric safety. ELSAF, pp. 118-127 (2001).

[4] Sajewicz D., Applying Bayesian Networks to management of electrical safety. Ph. D. dissertation. Białystok (2011).

[5] Korniluk W., Sajewicz D., Method of modelling shock safety of low-voltage equipment. Electrotechnical News 6: 18-24 (2009).

[6] PN-EN 61140, Protection against electric shocks. Joint aspects of installations and devices. Warsaw (2005).

[7] PN-HD 60363-4-41, Low-voltage electrical installations. Part 4-41: Protection for safety. Protection against electric shock. Warsaw (2005).

[8] Charoy A., Electromagnetic compatibility. Interference in electronic equipment. Wydawnictwa Naukowo-Techniczne, Warsaw (2000).

[9] Sobolewski R.A., Method of analysing electric shock risk for low-voltage equipment users. Ph. D. dissertation, Bialystok (2002).

[10] Sulkowski M.A., Method of analysing reliability of technical means of protection against electric shock in low-voltage equipment. Ph. D. dissertation, Białystok (2008).

[11] Korniluk W., Sajewicz D., Matching criteria for protection against electric shock - probabilistic approach. Electrotechnical News 7: 29-33 (2007).

[12] Lejdy B., Electrical installations for buildings. Wydawnictwa Naukowo-Techniczne, Warsaw (2005).

[13] Gulski E., Smit J. J., Maksymiuk J., Management of power network resources. Oficyna Wydawnicza Politechniki Warszawskiej, Warsaw (2004).

[14] PN-IEC 812, Analysis techniques for system reliability. Procedure for failure mode and effects analysis (1994). 